\title{
Studi Awal Pembuatan Membran Chitosan-Silica Based dari Berbagai Limbah
}

\author{
Preliminary Study on Chitosan-Silica Based Membrane Production from Several Waste
}

\author{
Felix Arie Setiawan ${ }^{1 *}$, I Made Arimbawa ${ }^{1)}$, Navisa Ayudia Putri ${ }^{1)}$, Boy Arief Fachri $^{1)}$ \\ 1) Universitas Jember, Teknik Kimia, Indonesia \\ *email: felix.arie@unej.ac.id
}

Received: 25/12/19; Revised: 09/06/20; Accepted: 09/06/20

\begin{abstract}
Abstrak
Jember memiliki potensi perikanan terutama udang sebagai sumber kitin yang merupakan dasar pembuatan kitosan. Kitosan berasal dari limbah kulit udang yang dicampur dengan limbah lain yaitu padatan silika dari Pembangkit Listrik Panas Bumi dan fly ash dari Pembangkit Listrik Tenaga Uap untuk menghasilkan membran yang dapat digunakan dalam filtrasi logam berat dalam air. Membran tanpa silika dibuat sebagai negative control dan dengan silika murni sebagai positive control. Membran kitosan dibuat dengan cara mencampurkan 1,0 gram kitosan dalam $100 \mathrm{~mL}$ larutan asam asetat $2 \% \mathrm{v} / \mathrm{v}$ dan 0,8 gram senyawa silika serta 0,5 gram polyethylene glycol. Membran yang telah dibuat diuji untuk menyaring larutan yang mengandung logam berat $\mathrm{Cu}$ dan $\mathrm{Pb}$. Konsentratsi optimum dari $\mathrm{Cu}$ dan $\mathrm{Pb}$ dalam badan cairan dapat dikurangi sebesar $87 \%$ dan $80 \%$ menggunakan membran kitosan-silika.
\end{abstract}

Kata kunci: kitosan, logam berat, membran, power plant waste, silika

\begin{abstract}
Jember has fishery potential, especially shrimp as a source of chitin which is the basis for making chitosan. Chitosan from waste is mixed with other wastes, namely silica solids from the Geothermal Power Plant and fly ash from the Power Plant to produce membranes that can be used in heavy metal filtration. In addition, membranes without silica are made as negative control and with pure silica as positive control. Chitosan membrane was made by mixing 1.0 gram of chitosan in $100 \mathrm{~mL}$ of $2 \% \mathrm{v} / \mathrm{v}$ acetic acid solution, 0.8 gram of silica compound, and 0.5 gram of polyethylene glycol. Membranes were tested to filter out solutions containing heavy metals of $\mathrm{Cu}$ and $\mathrm{Pb}$. The optimum concentrations of $\mathrm{Cu}$ and $\mathrm{Pb}$ in solution can be reduced by $87 \%$ and $80 \%$ using chitosan-silica membranes, respectively.
\end{abstract}

Keywords: chitosan, heavy metals, membrane, power plant waste, silica

\section{PENDAHULUAN}

Jember yang terletak di wilayah pesisir selatan Pulau Jawa memiliki potensi perikanan yang sangat besar. Potensi tangkapan udang di wilayah Jember tidak dapat dipandang sebelah mata dan cukup tinggi seperti terlihat pada Tabel 1 , rerata tangkapan nelayan sebesar 25,5 Ton per tahun. Udang merupakan hewan laut yang memiliki kandungan zat kitin $15-20 \%$ pada kulitnya (Focher dkk., 1992). Menurut data BPS tahun 2002 (BPS, 2002), jumlah total limbah udang sebesar $29,7 \%$ dari berat aslinya. Sehingga potensi limbah udang di wilayah Jember per tahun adalah sekitar 7,6 ton. 
Meninjau potensi pemanfaatan limbah kulit udang setiap tahun, perlu upaya studi untuk membuat suatu produk turunannya. Zat kitin yang terkandung dalam limbah udang sebenarnya dapat diolah menjadi kitosan yang memiliki nilai jual tinggi. Kitosan memiliki beragam aplikasi di berbagai bidang seperti kesehatan, pemurnian air (koagulan untuk pengolahan limbah), aplikasi biomedis, pertanian, bioteknologi, nutrisi, dan pengisi serat tekstil (Fernandez-Kim, 2004). Penelitian mengenai pemanfaatan kitosan sebagai membran sudah banyak dilakukan (Cui $d k k ., 2018$; Li $d k k ., 2018$; Visa, 2016; Yang $d k k .$, 2019). Aplikasi membran kitosan sangat beragam baik pada ranah medis dan kecantikan maupun skala industri seperti pengolahan air dan adsorben.

Penelitian ini berfokus pada pemanfaatan kitosan untuk digunakan sebagai membran pengolahan air dalam mengurangi logam berat. Keberadaan logam berat di dalam air mempunyai nilai ambang batas yang harus disesuaikan dengan baku mutu air. Kitosan memiliki beberapa kelemahan sebagai membran sehingga banyak penelitian yang mencoba menggabungkan kitosan dengan material pengisi (porogen) untuk menunjang kemampuan dan sifatnya. Secara umum, porogen untuk membran berbasis kitosan adalah polietilen glikol, polivinil pirolidin, silika, dan garam (He dkk., 2009, Kalapathy $d k k$., 2000, Mahatmanti $d k k$., 2016, Zeng \& Fang, 2004, Zhang $d k k$., 2002, Zulti $d k k$., 2013). Penambahan silika dalam biomaterial kitosan dapat meningkatkan permeabilitas terhadap oksigen, serta ketahanan fisik terhadap suhu tinggi (Muljani $d k k$., 2018).
Tabel 1. Hasil Perikanan Kabupaten Jember dalam ton (Pemkab-Jember, 2016)

\begin{tabular}{cccc}
\hline Jenis & \multicolumn{3}{c}{ Tahun } \\
\cline { 2 - 4 } ikan & $\mathbf{2 0 0 9}$ & $\mathbf{2 0 1 0}$ & $\mathbf{2 0 1 1}$ \\
\hline Tuna & 415,0 & 401,5 & 946,4 \\
\cline { 3 - 4 } Cakalang & 1839,9 & 1979,0 & 1965,0 \\
Tongkol & 1628,9 & 1624,9 & 1991,1 \\
Tengiri & 117,2 & 116,6 & 415,7 \\
Udang & 24,5 & 16,0 & 36,1 \\
\hline
\end{tabular}

Penelitian ini telah menggabungkan kitosan yang diperoleh dari limbah udang dengan limbah silika dari Pembangkit Listrik Tenaga Panas Bumi (PLTPB) berupa padatan silika dan limbah silika dari Pembangkit Listrik Tenaga Uap berupa fly ash. Limbah silika dari PLTPB pada penelitian ini diperoleh dari PLTPB Dieng dan fly ash diperoleh dari Pembangkit Listrik Arutmin. Beberapa penelitian menggabungkan silika ke dalam membran kitosan yang diambil dari ampas tebu (Sjamsiah $d k k$., 2017), sekam padi (Bokau, 2013), dan limbah silika PLTPB (Muljani dkk., 2018). Penelitian ini mengkaji aplikasi dan pengaruh penambahan padatan silika dari limbah PLTPB dan fly ash terhadap filtrasi logam berat.

\section{METODE PENELITIAN}

Bahan yang digunakan dalam penelitian ini adalah kitosan, limbah silika padatan dari PLTPB Dieng, fly ash dari PTLU Arutmin, asam asetat, $\mathrm{NaOH}, \mathrm{HCl}$, Polyethylene glycol (PEG), $\mathrm{Pb}\left(\mathrm{NO}_{3}\right)_{2}$, dan $\mathrm{CuSO}_{4}$. Semua bahan yang digunakan merupakan grade pro analisis.

Membran kitosan dibuat dengan cara mencampurkan 1,0 gram kitosan dalam $100 \mathrm{~mL}$ larutan asam asetat $2 \% \mathrm{v} / \mathrm{v}$ dan 0,8 gram senyawa silika dan 0,5 gram PEG. Silika yang digunakan dalam penelitian ini terdiri dari dua yaitu silika dari sumber fly ash dan limbah PLTPB, masing-masing 
sebanyak 0,8 gram. Campuran diaduk hingga homogen dan tidak terdapat gelembung udara di dalam larutan. Senyawa silika terlebih dahulu dicampur dengan $\mathrm{NaOH} 0,1 \mathrm{M}$ selama 15 menit untuk mencuci limbah fly ash dan limbah PLTPB kemudian dilanjutkan proses pengovenan. Setelah itu, pada membran kitosan dilakukan penambahan PEG sebagai Negative Control (NC) dan penambahan silika gel 70 - 230 mesh sebagai Positive Control (PC). Membran diperoleh dengan menuangkan larutan di atas cawan petri dan dibiarkan selama 3 hari untuk menguapkan pelarut yang ada selama 3 hari. Membran dinetralkan dengan larutan $\mathrm{NaOH} 5 \%(\mathrm{~b} / \mathrm{v})$ setelah proses penguapan pelarut. Membran kemudian dicuci menggunakan $\mathrm{HCl} \mathrm{0,1} \mathrm{M}$ untuk menghilangkan $\mathrm{NaOH}$ tersisa yang dilanjutkan dengan pencucian menggunakan akuades sebanyak 5 kali. Membran yang sudah dicuci akan disimpan dalam desikator selama 3 hari.

Logam berat dibuat dengan mencampurkan 2,512 gram kristal CuSO dalam $1 \mathrm{~L}$ akuades untuk membuat larutan induk $\mathrm{CuSO}_{4}$ sebesar 1000 ppm. Sedangkan larutan $\mathrm{PbCl}_{2}$ dibuat dengan 0,15999 gram dalam $1 \mathrm{~L}$ akuades untuk membuat larutan induk $\mathrm{PbCl}_{2}$ sebesar 1000 ppm. Larutan induk $\mathrm{CuSO}_{4}$ dan $\mathrm{PbCl}_{2}$ sebesar $10 \mathrm{~mL}$ dan $35 \mathrm{~mL}$ dimasukkan ke dalam $100 \mathrm{~mL}$ labu ukur dengan ditambah larutan $\mathrm{HCl} 1 \mathrm{M}$ sebanyak $1 \mathrm{~mL}$ dan ditambahkan akuades sampai penuh sehingga diperoleh larutan logam berat yang akan diuji.

Membran diuji kemampuan dalam filtrasi logam berat yang terkandung pada larutan logam berat yang telah dibuat. Membran dicelupkan ke dalam larutan logam berat dan setelah 24 jam diambil sampel untuk diukur kandungan logam beratnya. Percobaan dilakukan secara duplo. Filtrat yang diambil dianalisis menggunakan AAS untuk mengetahui kandungan logam berat yang tersisa di dalam larutan.

\section{HASIL DAN PEMBAHASAN}

Membran dari kitosan dan silika telah berhasil dibuat seperti tersaji dalam Gambar 1. Gambar tersebut menunjukkan beberapa konsentrasi silika dan jenis silika yang dimasukkan ke dalam larutan kitosan. Membran murni mengandung kitosan berwarna transparan yang disebut dengan Negative Control (NC) sedangkan pada berbagai variasi silika campuran baik dari limbah PLTPB dan fly ash menunjukkan warna yang semakin hitam (campuran fly ash lebih banyak) dan terakhir merupakan silika yang terbuat dari kitosan dicampur dengan silika murni atau yang disebut Positive Control (PC).

Proses pencelupan dilakukan dalam penelitian ini dan bukan proses filtrasi dikarenakan membran kitosan yang mudah robek apabila dilakukan perlakuan aliran. Oleh karena itu, proses pencelupan diharapkan mampu digunakan untuk menggantikan proses filtrasi. Sifat fisis dari membran kitosan-silika ini perlu juga diperbaiki agar dapat digunakan pada skala industri. Hal ini lebih dikarenakan sifat dari kitosan yang kurang terhadap pelarut polar. Penambahan bahan aktif lain untuk meningkatkan sifat fisik dari kitosan selain dari sifat penyaringan logam berat dibutuhkan untuk meningkatkan penggunaan kitosan dalam dunia industri. 


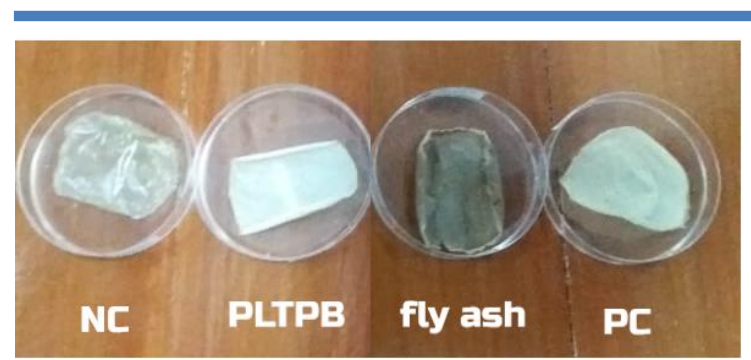

Gambar 1. Membran yang dibuat dari kitosan dan silika

Pengujian komposisi kimia limbah fly ash dan limbah PLTPB dilakukan untuk mengetahui kandungan penyusunnya. Spektrum dapat dilihat Pada Gambar 2 dan komponen kimia pada Tabel 2. Gambar 2 memperlihatkan spektrum komposisi kimia yang terkandung dalam fly ash dan limbah PLTPB. Limbah PLTPB masih terdapat banyak noise dikarenakan banyaknya interference dalam limbah tersebut, sehingga persiapan limbah PLTPB harus diperhatikan dengan lebih seksama dalam hal pencucian dibanding dengan limbah fly ash. Namun, limbah PLTPB mempunyai kandungan silika yang lebih banyak daripada limbah fly ash seperti terlihat pada Tabel 2. Hal ini akan mempengaruhi kualitas membran yang akan dibuat.

Tabel 2. Hasil Analisis Bahan Baku Menggunakan XRF

\begin{tabular}{ccc}
\hline Komposisi & $\begin{array}{c}\text { Fly ash, } \\
\text { \% }\end{array}$ & $\begin{array}{c}\text { Limbah PLTPB, } \\
\text { \% }\end{array}$ \\
\hline $\mathrm{Si}$ & 44,6 & 89,058 \\
$\mathrm{Fe}$ & 33,847 & 8,933 \\
$\mathrm{Al}$ & 10,778 & $<\mathrm{LOD}$ \\
$\mathrm{Ti}$ & 1,073 & $<\mathrm{LOD}$ \\
$\mathrm{Mn}$ & 0,429 & $<\mathrm{LOD}$ \\
$\mathrm{Cr}$ & 0,057 & 1,501 \\
$\mathrm{~V}$ & 0,132 & 0,506 \\
\hline
\end{tabular}

Hasil aplikasi membran kitosansilika dapat dilihat pada Tabel 3 dalam filtrasi logam berat. Membran kitosansilika terlihat lebih efektif untuk filtrasi logam $\mathrm{Cu}$ dibandingkan dengan logam $\mathrm{Pb}$.
Hal ini dikarenakan ukuran atom $\mathrm{Cu}$ yang lebih besar daripada $\mathrm{Pb}$ dalam pelarutnya yang berupa $\mathrm{HCl}$ yang merupakan alasan utama dalam filtrasi logam berat ini. Diameter senyawa $\mathrm{CuCl}_{2}$ dan $\mathrm{PbCl}_{2}$ mempunyai ukuran sebesar $31 \mu \mathrm{m}$ dan

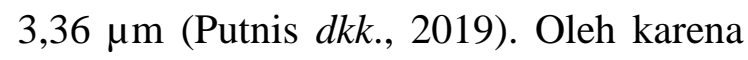
itu, senyawa $\mathrm{PbCl}_{2}$ akan lebih mudah lolos dan terikut ke dalam filtrat.

Tabel 3. Konsentrasi Logam Berat dalam Aplikasi Membran

\begin{tabular}{lcrrr}
\hline \multirow{2}{*}{ Sample } & \multicolumn{2}{c}{ Cu, ppm } & \multicolumn{2}{c}{ Pb, ppm } \\
\cline { 2 - 5 } & Awal & Akhir & Awal & \multicolumn{1}{c}{ Akhir } \\
\hline PC & 11,19 & 1,10 & 36,77 & 4,80 \\
PLTPB & 11,19 & 1,41 & 36,77 & 7,43 \\
Fly ash & 11,19 & 1,90 & 36,77 & 7,98 \\
NC & 11,19 & 1,89 & 36,77 & 13,88 \\
\hline
\end{tabular}

Untuk melihat keefektifan dari membran yang telah dibuat, maka persen penyaringan dapat dilihat pada Gambar 3, proses penyaringan (a) logam $\mathrm{Cu}$ sedangkan (b) untuk logam $\mathrm{Pb}$. Berdasarkan hasil tersebut, diketahui bahwa PC sangat baik dalam menyaring logam berat dibandingkan dengan membran lain. Hal ini karena PC mengandung senyawa silika murni yang dapat membantu dalam proses penyaringan logam berat dalam larutan. Selain itu, campuran membran yang mengandung limbah PLTPB lebih efektif dalam proses filtrasi logam berat. Hal ini disebabkan oleh tingginya kandungan silika yang terdapat dalam limbah PLTPB yang membantu proses filtrasi logam berat. 
Felix Arie Setiawan*), I Made Arimbawa, Navisa Ayudia Putri, Boy Arief Fachri

\section{Studi Awal Pembuatan Membran Chitosan-Silica Based dari Berbagai Limbah}

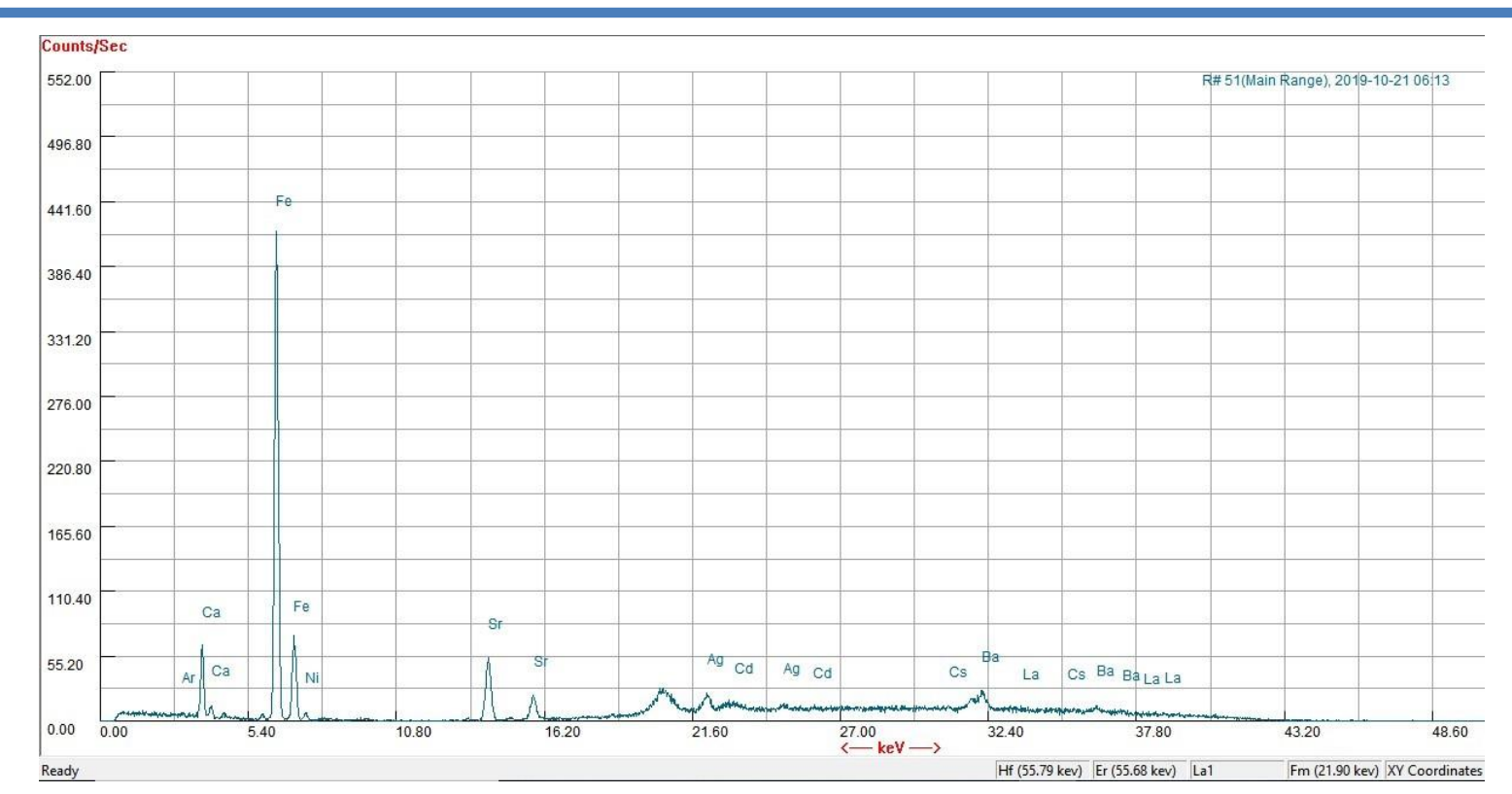

(a)

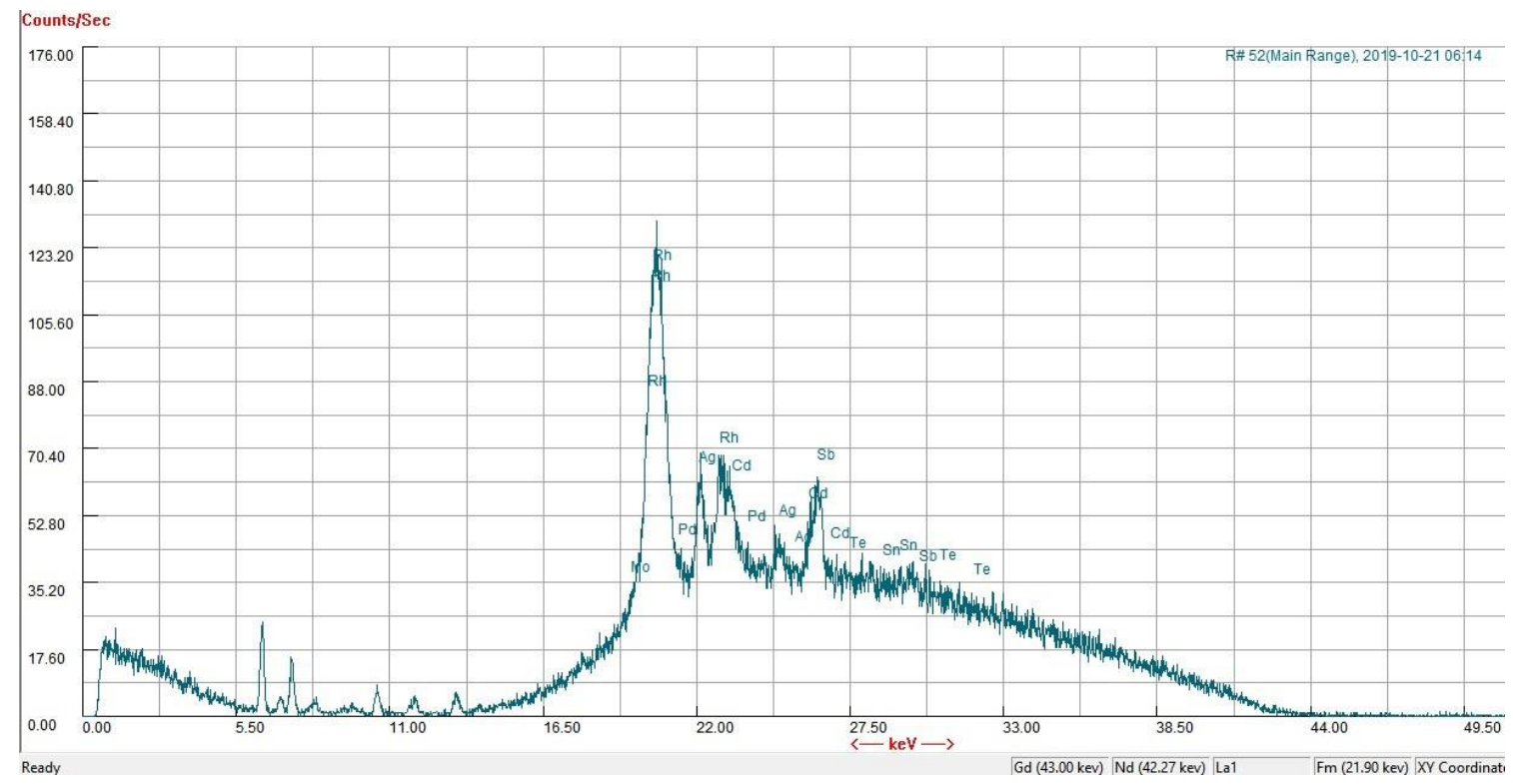

(b)

Gambar 2. XRF Spectrum untuk Sampel (a) fly ash dan (b) limbah PLTPB
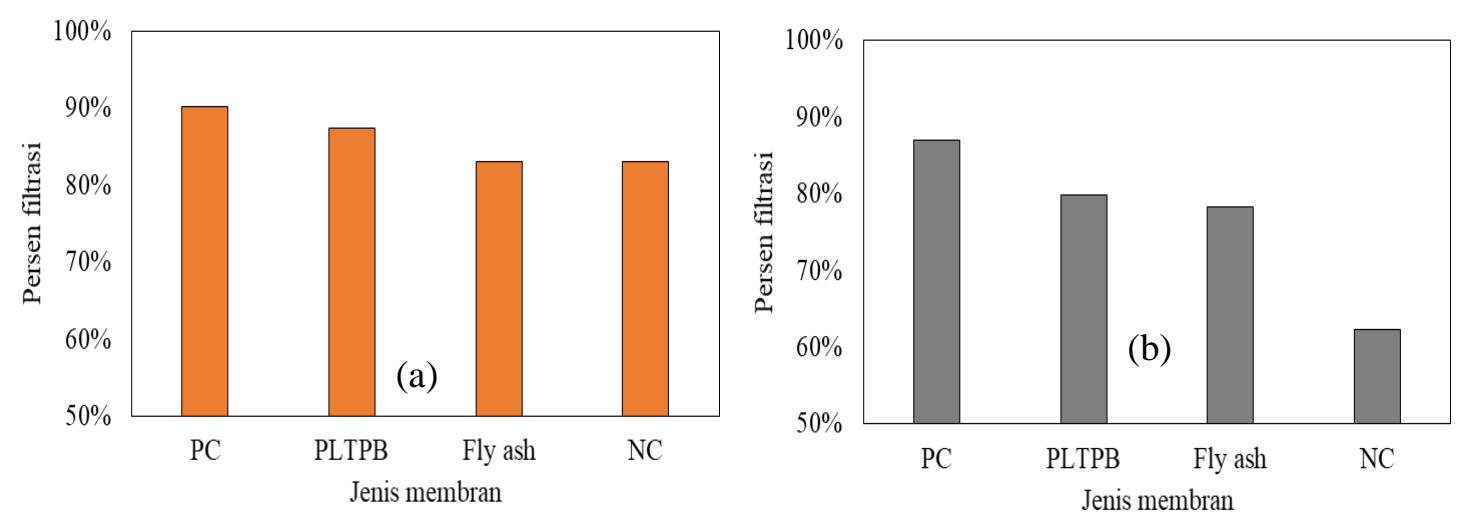

Gambar 3. Besarnya logam berat yang tersaring (a) $\mathrm{Cu}$ dan (b) $\mathrm{Pb}$ 
Pada proses penyaringan yang terjadi masih terdapat kelemahan dalam membran yang digunakan. Hal ini dikarenakan membran yang telah digunakan untuk menyaring tidak dapat digunakan lagi karena sifat dari membran kitosan yang hidrophilic dan menyerap air terlalu banyak. Pada kondisi tersebut, membran dapat mudah robek dan tidak dapat digunakan kembali.

\section{KESIMPULAN}

Penelitian ini dapat menyimpulkan bahwa limbah PLTPB sangat efektif dalam proses penyaringan logam berat di dalam larutan. Akan tetapi, Penelitian lebih lanjut perlu dilakukan untuk meninjau proses penyaringan sebagai fungsi waktu dalam melihat keefektifan dari membran yang dibuat. Selain itu, bahan lain perlu ditambahkan dalam pembuatan membran ini untuk mencegah proses swelling dalam penggunaan membran kitosan silika agar dapat digunakan kembali.

Membran berbasis kitosan dan silika yang dihasilkan dari limbah PLTPB dan PLTU telah berhasil dibuat. Membran ini juga sangat efektif dalam proses penyaringan logam berat dalam air. Proses filtrasi $\mathrm{Cu}$ lebih efektif dibandingkan dengan $\mathrm{Pb}$ dengan persen filtrasi optimum adalah $87 \%$ menggunakan membran dari limbah PLTPB. Sedangkan $\mathrm{Pb}$ yang dapat diambil dari larutan sebesar $80 \%$.

\section{DAFTAR RUJUKAN}

Bokau, N. S. (2013). Sintesis Membran Kitosan Termodifikasi Silika Abu Sekam Padi untuk Proses Dekolorisasi. Universitas Negeri Semarang.

BPS. (2002). Jurnal Ekspor Perdagangan Luar Negeri Indonesia. Jakarta

Cui, L., Gao, S., Song, X., Huang, L., Dong, H., Liu, J., Chen, F., \& Yu, S.
(2018). Preparation and characterization of chitosan membranes. RSC Adv., 8(50), 28433 28439 ,

https://doi.org/10.1039/C8RA05526 $\underline{B}$

Fernandez-Kim, Sun-Ok. (2004). Physicochemical and functional properties of crawfish chitosan as affected by different processing protocols. Thesis: Louisiana State University,

https://digitalcommons.lsu.edu/cgi/vi ewcontent.cgi? article $=2337 \&$ context =gradschool theses

Focher, B., Naggi, A., Torri, G., Cosani, A., \& Terbojevich, M. (1992). Structural differences between chitin polymorphs and their precipitates from solutions-evidence from CPMAS 13C-NMR, FT-IR and FTRaman spectroscopy. Carbohydrate Polymers, 17(2), 97-102, https://doi.org/10.1016/01448617(92)90101-U

He, L.-h., Xue, R., Yang, D.-b., Liu, Y., \& Song, R. (2009). Effects of blending chitosan with PEG on surface morphology, crystallization and thermal properties. Chinese Journal of Polymer Science, 27(04), 501-510, https://www.worldscientific.com/doi/ pdf/10.1142/S0256767909004175

Kalapathy, U., Proctor, A., \& Shultz, J. (2000). Production and properties of flexible sodium silicate films from rice hull ash silica. Bioresource technology, 72(2), 99-106, https://doi.org/10.1016/S09608524(99)00112-1

Li, C., Lou, T., Yan, X., Long, Y.-Z., Cui, G., \& Wang, X. (2018). Fabrication of pure chitosan nanofibrous membranes as effective absorbent for dye removal. International journal of biological macromolecules, 106, 768-774, https://doi.org/10.1016/j.ijbiomac. 20 $\underline{17.08 .072}$ 
Mahatmanti, F. W., Nuryono, N., \& Narsito, N. (2016). Adsorption of Ca (II), $\mathrm{Mg}$ (II), $\mathrm{Zn}$ (II), and Cd (II) on Chitosan Membrane Blended with Rice Hull Ash Silica and Polyethylene Glycol. Indonesian Journal of Chemistry, 16(1), 45-52, https://jurnal.ugm.ac.id/ijc/article/vie $\mathrm{w} / 21176$

Muljani, S., Kusuma, K. A., Nofitasari, L., Amalia, A. R., \& Hapsari, N. (2018). Sintesis Membran Kitosan Silika Dari Geothermal Sludge. Jurnal Teknik Kimia, 13(1), https://doi.org/10.33005/tekkim.v13i $\underline{1.1150}$

Pemkab-Jember. (2016). Kelautan dan perikanan. Retrieved from http://www.jemberkab.go.id/kelautan -dan-perikanan/

Putnis, C. V. (2019). Editorial for Special Issue "Mineral Surface Reactions at the Nanoscale". Minerals, 9(3), 185, https://doi.org/10.3390/min9030185

Sjamsiah, S., Ramadani, K., \& Hermawan, H. (2017). Sintesis Membran Silika Kitosan Dari Abu Ampas Tebu (Bagasse). Al-Kimia, 5(1), 81-88, http://journal.uin-

alauddin.ac.id/index.php/alkimia/article/view/2857

Visa, M. (2016). Synthesis and characterization of new zeolite materials obtained from fly ash for heavy metals removal in advanced wastewater treatment. Powder Technology, 294, 338-347, https://doi.org/10.1016/j.powtec.201 6.02 .019

Yang, D., Li, L., Chen, B., Shi, S., Nie, J., \& Ma, G. (2019). Functionalized chitosan electrospun nanofiber membranes for heavy-metal removal. Polymer, 163, 74-85, https://doi.org/10.1016/j.polymer.201 $\underline{8.12 .046}$

Zeng, M., \& Fang, Z. (2004). Preparation of sub-micrometer porous membrane from chitosan/polyethylene glycol
semi-IPN. Journal of Membrane Science, 245(12), 95-102, https://doi.org/10.1016/j.memsci.200 4.08 .004

Zhang, M., Li, X., Gong, Y., Zhao, N., \& Zhang, X. (2002). Properties and biocompatibility of chitosan films modified by blending with PEG. Biomaterials, 23(13), 2641-2648, https://doi.org/10.1016/S01429612(01)00403-3

Zulti, F., Dahlan, K., \& Sugita, P. (2013). Adsorption of Waste Metal Cr (VI) with Composite Membranes (Chitosan-Silica Rice Husks). Makara Journal of Science, 163-168, http://journal.ui.ac.id/index.php/scien ce/article/view/1477 